\title{
Nutritional Proteomics: Methods and Concepts for Research in Nutritional Science
}

\author{
Florian J. Schweigert \\ Department of Physiology and Pathophysiology, Institute of Nutritional Science, University of Potsdam, \\ Potsdam-Rehbrücke, Germany
}

\section{Key Words}

Nutritional science $\cdot$ Proteomics • Microheterogeneity •

Protein complexes $\cdot$ Biomarker $\cdot$ Nutriproteomics

\begin{abstract}
Nutritional proteomics or nutriproteomics is the application of proteomics methodology to nutrition-related research but also represents the interaction of bioactive food ingredients with proteins, whereby the interaction with proteins occurs in two basically specific ways. Firstly, the effect of nutrients on protein expression, which can be monitored by protein mapping, and secondly, the interaction of nutrients with proteins by post-translational modifications or smallmolecule protein interactions. These interactions result in changes to the three-dimensional structure of such effected proteins. As a consequence, their original functions are modulated, resulting for example in reduced activity in the case of enzymes or changes in ability of recognition between molecules such as protein-protein interactions and ligand-receptor interactions. The characterization of such modifications together with functional data from established biochemical and physiological methods will result in a better understanding of the interplay between bioactive dietary components and diet-related diseases such as cancer, diabetes or neurodegenerative diseases. The occurrence of such modifications can possibly be additionally used as biomarkers in the diagnosis and therapy of these diseases as well as biomarkers for the efficacy or safety of selected nutrients.
\end{abstract}

Copyright $\odot 2007$ S. Karger AG, Basel

\section{KARGER}

Fax +4161306 1234 E-Mail karger@karger.ch www.karger.com
(C) 2007 S. Karger AG, Basel

0250-6807/07/0512-0099\$23.50/0

Accessible online at:

www.karger.com/anm

\section{Proteomics}

Over the past 30 years, biological science has been centered on the quest to reveal the nature of the human genetic make-up, culminating in the documentation of the complete sequence of the human genome [1]. Despite the fact that the coding occurs on a mere $30,000-40,000$ genes, the corresponding proteome is much more complex than this perhaps implies. Events such as alternative splicing and post-translational modifications generate a highly diverse set of proteins that could exceed a million structurally distinct molecular species. These molecules may all have different functions in the organism. In many cases, it is thus likely that concentrations of specific proteins do not change significantly, but rather their function is modulated by post-translational modifications [2-5]. Additionally, proteins may vary in function depending on whether or not they interact with other proteins [6].

The proteome, defined as the protein complement expressed by a genome, implies a static nature but is in reality highly dynamic. The types of proteins expressed and their abundance and state of modification to name but few aspects, are all dependent on the physiological or pathophysiological state of the cell or the tissue. Thus, the proteome reflects the cellular state or the external conditions encountered by an organism. Proteomics may therefore be defined as the different methodologies used to describe the structural diversity of proteins and the correlation of this diversity with the underlying biological processes.

Florian J. Schweigert

Institute of Nutritional Science, University of Potsdam

Arthur-Scheunert-Allee 114-116, DE-14558 Potsdam-Rehbrücke (Germany)

Tel. +49 3320088 527/528, Fax +4933 20088573

E-Mail schweigert@nutriproteomics.de 


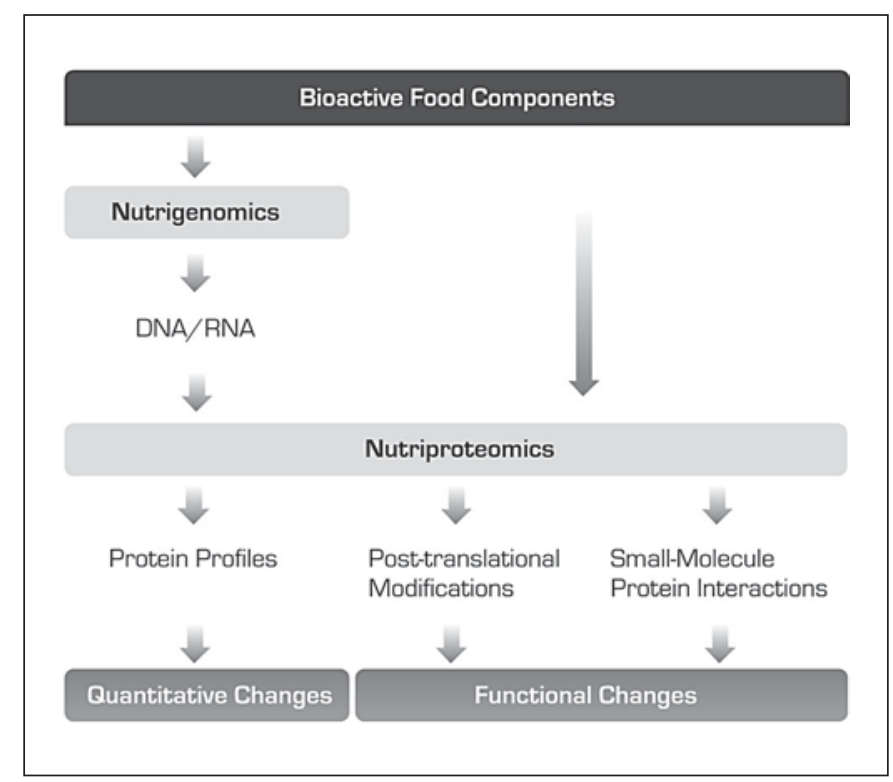

Fig. 1. Nutritional proteomics characterizes the interaction of bioactive food ingredients with the proteome.

\section{Nutritional Proteomics}

We are currently encountering substantial progress in nutritional knowledge with relevance to the practice of all aspects of human nutrition, medicine and public health. Based on this progress, we will view the role of nutrition differently in the future. We are aware that diet may not only provide an adequate amount of nutrients to meet the metabolic requirements, but could also contribute to improving human health status. As a consequence of this awareness, plant extracts or single compounds thereof which benefit human health need to be identified and developed for the food market to complement a balanced diet. The task will be to evaluate both compounds and target structures. The possible target structures, on a cellular and molecular level, as well as the enormous number of bioactive compounds to be tested represent a very hetergenous group of molecular structures. This means that this task will present a challenge to all scientific disciplines.

Nutritional proteomics or nutriproteomics is not only the application of proteomics methodology to nutritionrelated research but also represents the interaction of bioactive food ingredients with proteins, whereby the interaction with proteins occurs in two basically specific ways. Firstly, the effect of bioactive food ingredients on protein synthesis via gene expression and secondly the interaction of these ingredients with proteins via posttranslational modifications or small-molecule protein interactions. In the case of post-translational modifications through covalent or non-covalent interaction of specific bioactive nutrients with peptides or proteins the three-dimensional structure is changed. As a consequence of these structural changes, the original functions of peptides and proteins are modulated resulting for example in reduced activity as in the case of enzymes or changes in ability of the recognition between molecules such as protein-protein interactions or ligand-receptor interactions (fig. 1). The characterization of such modifications together with functional data from established biochemical and physiological methods will result in a better understanding of the interplay between dietary components and diet-related diseases such as cancer, diabetes or neurodegenerative diseases. The occurrence of such modifications can possibly be used as biomarkers in the diagnosis and therapy of these diseases as well as biomarkers for the efficacy or safety of selected nutrients.

On the whole, studies currently addressing proteomic aspects in relation to nutritional research use classical methods to look at changes in peptide and protein patterns (protein mapping or profiling) $[7,8]$. In-depth reviews addressing the methodological issues are available [9-16].

\section{Protein Mapping}

Unlike the genome, the proteome is dynamic and constantly changing in response to a cell's or organism's environment. The variety of proteins present and their relative abundance changes in response to such phenomena as stress, diseases or drug treatment. Comparing the proteome under varying conditions gives the means to identify key proteins involved for example in a particular disease process. Classical two-dimensional electrophoresis technologies capable of analyzing the protein content of cells and tissues as well as body fluids such as plasma or urine in combination with mass spectrometry (MS) are applied. Despite many introduced improvements, twodimensional electrophoresis will probably remain a rather low-throughput approach that requires a relatively large amount of sample. In theory, establishing protein maps or profiles should be relatively straightforward, however in practice this is indeed a huge challenge. The protein complement of a body fluid or cell may run into thousands of different proteins and the abundant varia- 
tion between these proteins - the dynamic range - differs in blood plasma by a factor of 100,000. Furthermore, nine proteins (e.g. albumin, immunoglobulins, transferring, fibrinogen and haptoglobulin) make up $90 \%$ of plasma proteins $[17,18]$. This makes the detection of low-abundant proteins, which might be important regulators of physiological processes and mediators of diseases very difficult when using electrophoresis and MS.

Undoubtedly, various non-gel-based methods that rely on liquid-based separations with or without tagging of peptides and proteins and other on-chip separation approaches such as surface-enhanced laser desorption/ionization time-of-flight MS (SELDI-TOF-MS) have great potential for the automation of direct profiling [19-21].

With regard to nutritional application of protein mapping, different studies have shown that a single ingredient such as a mineral, vitamin or other substances derived from plants [22-25] or specific diets [26] can modulate the protein pattern of organs such as the liver or body fluids like blood plasma. When using protein mapping as an analytical approach, one has to realize that the display of as many protein signals as possible or achieving the greatest number of positive identifications represents a challenging and worthy technical goal. However, major progress will be achieved by applying approaches that directly contribute to the elucidation and validation of biological functions.

\section{Functional Proteomics}

Proteins do not work in isolation but exert their effects by forming complexes with other molecules. The behavior, morphology and response to stimuli in biological systems are dictated by the interactions between their components. These interacting molecules can be other proteins or metabolites. A well-established and characterized example for this functional relationship among proteins and small molecules is the intracellular signaling system or the inflammatory response of the organism [27-29]. In this context, changes in protein structure and/or abundance can have significant impact on physiological processes or disease initiation and progression.

Optimally, protein interactions can be used to isolate molecules from a solution and can simultaneously provide functional information about the nature of the binding interaction in terms of affinity and specificity. Chipbased analytical formats have greatly advanced interaction studies by automation and miniaturization of protein capture processes. The basic concept is to immobilize the target protein on the chip surface. This can either be a specific antibody as bait for the protein in question and its interaction partners or the protein itself that captures potential binding partners out of complex matrixes such as blood plasma or cell lysate. The use of antibodies as bait is especially useful for characterizing the microheterogeneity of proteins [30]. Depending on the technology used, these analytical approaches can provide real-time kinetic information and in combination with MS mass and sequence characterization, also additional information on function [31-35].

\section{Protein Microheterogeneity and Small-Molecule Protein Interaction}

Protein microheterogeneity can be caused by simple proteolysis or by various sophisticated post-translational modifications. These modifications range from the widespread, such as glycosylation, phosphorylation, ubiquitination and methylation to the less frequent ones such as glutathioylation, hydroxylation, sulfation and transglutamination. It has been estimated that more than $50 \%$ of all known proteins are glycosylated [36]. This aspect of modification has recently been summarized under the term heteromics [30]. These often small differences between two proteins, for instance, a single amino acid modification, often have important influences on the function of the protein. Such functions include secretion, plasma transport, receptor binding, degradation and excretion but may also influence protein-protein complex formation as well. Thus, post-translational modification can create a dynamic combinational library of properties that rapidly respond to physiological or pathophysiological stimuli [37-41].

With regard to the interaction of single nutrients with proteins, numerous studies address the question as to which extent single components in a specific diet might interact with food proteins. Non-covalent and covalent modifications have been observed for the interaction of selected secondary plant products (e.g., glucosinolate breakdown products, phenolic compounds) with a series of proteins, addressing both food technological and physiological aspects of human nutrition [42-44]. Beside changes in protein structure and conformation $[45,46]$, additional functional consequences were observed with regard to modifications induced by dietary components such as reduction of nutritional protein quality, enzymatic activity in cases of modified enzymes and masking of the biological properties of the reacting small nutrients 
(e.g. antioxidant potential of the phenolic compounds). For example, both $\alpha$-chymotrypsin and $\alpha$-amylase can be modified by covalent attachment of phenolic and related components such as caffeic acid, chlorogenic acid, ferulic acid, gallic acid, quinic acid and $\rho$-benzoquinone. The formed derivates showed reduced in vitro enzyme activity towards food proteins or starch [42, 47, 48]. This strongly supports the concept that conformational changes in proteins can be induced by the interaction of nutrients with specific proteins and that these changes are of functional consequence for the organism.

While there is a growing number of investigations on the level of interaction between dietary ingredients such as small molecules with dietary proteins, very few in-vitro and as yet no in-vivo studies are available regarding individual proteins of the body, whereby preliminary invitro studies with serum and saliva proteins do confirm the potential of such interactions [43]. Comparable effects can certainly be expected from selected nutrients. Dietary components such as diallyl disulfide (DADS), a compound found in processed garlic, have been shown to post-translationally modify proteins. The exposure of cells to DADS did not effect the protein concentration of extracellular signal-regulated kinase (ERK) but its phosphorylation which resulted in a modification of activity and finally arrest of the cell cycle [49]. Other studies show that the post-translational regulation of proteins by dietary components involves the modification of the thiol groups of selected proteins [50]. A very recent experiment with regard to this question shows that oleocanthal, a component of olive oil, acts as a natural antiinflammatory compound by inhibiting cyclooxyganese enzymes in the prostaglandin-biosynthesis pathway in a similar way to the pharmacological component ibuprofen [51].

Other than in the field of nutritional science, many pharmacological studies do address the interaction of small molecules such as drugs with plasma proteins as part of their ADMET (absorption-distribution-metabolism-excretion-toxicology) evaluation. The reason for this is that protein binding (small-molecule protein interactions) in plasma greatly determines the metabolic fate of a given drug [52-56]. More importantly, in pharmacology, small molecules acting as antagonists to protein function are promising new drug candidates. Proteins targeted by theses small molecule antagonists fall into three classes: enzymes, cellular receptors and proteins involved in protein-protein interactions $[6,28$, $57,58]$.

\section{Protein-Protein Interactions}

Protein-protein interactions play a key role in most biological processes - from intracellular communication to programmed cell death. Beside the involvement of such interactions in intracellular signaling, the interaction of proteins in blood plasma contributes to modulations in plasma homoeostasis, receptor binding, degradation or protein excretion through, for instance, glomerular filtration [59]. Examples for these proteins are insulin-like growth factor-binding protein, tumor necrosis factorbinding protein and transthyretin (TTR) [18]. Because of these key roles in such biological processes, protein-protein interactions represent a large and important class of targets for therapeutics. The overall description of such protein-protein interactions is summarized with the term interactomics.

In order for two or more proteins to recognize each other and bind in solution, the protein surfaces involved in protein-protein interaction must share a great deal of charged amino acids that are complementary in both shape and juxtaposition. It is thus understandable that any alteration to the surface shape of a protein in a region crucial to the formation of protein-protein interactions will disrupt complementarity and will antagonize the association kinetics and thermodynamics of a protein-protein complex. Such surface changes are not only caused by small molecules that attach to critical regions of the protein, but also by post-translational modifications.

Thus, monitoring post-translational modifications as well as protein-protein interactions are two important tasks due to their potential impact on our understanding of protein function in health and disease. Within the field of functional proteomics, the aim of these two aspects, defined as heteromics and interactomics, is the characterization of structural and functional properties of proteins such as their interaction with other proteins $[60,61]$. Despite the great importance of post-translational modifications and protein-protein interactions for biological function, extended study of these aspects has been hampered by the lack of suitable high-throughput methods. Results would provide the basis for substantial progress in the diagnostic with regard to personalized medicine and eventually personalized nutrition $[62,63]$.

Since TTR fulfills both the aforementioned aspects, namely its occurrence in a post-translationally modified form as well as in a protein-protein complex with retinolbinding protein (RBP), it can be ideally used to illustrate these characteristics. 


\section{Transthyretin and Retinol-Binding Protein, an Example for Protein Microheterogeneity and Protein-Protein Interaction}

TTR is a multifunctional protein which interacts with several molecules of biological interest. Both its interaction with RBP and its binding property for thyroid hormones have been well established $[64,65]$ and recently further interactions and functions have been described [66]. Traditionally, TTR has been regarded as a biomarker for nutritional status as it is synthesized in the liver in response to nutritional supply. TTR plasma levels have thus been used as sensitive biochemical parameters of subclinical malnutrition, as both the adequacy of protein as well as energy intakes are reflected in its plasma levels. Plasma levels of TTR however, are also affected by acute and chronic diseases associated with an acute-phase response. Under these conditions, liver activity is concentrated on the synthesis of acute-phase response proteins, resulting in a drop in visceral proteins $[64,67]$. A truncated variant of TTR has been described as a biomarker for ovarian cancer [68], indicating a close interplay between nutritional status, inflammation and possibly the occurrence of cancer [69].

Both proteins RBP and TTR generally occur in plasma as a complex consisting of a homotetramer of TTR molecules with $\sim 14 \mathrm{kDa}$ and a RBP molecule with a molecular mass of $21 \mathrm{kDa}[64,70-72]$. After one-dimensional electrophoresis, both proteins can be detected by Western blotting in the complex matrix of plasma (fig. 2, lane a). An affinity enrichment of the complex using a polyclonal antibody against RBP for immunoprecipitation of the complex (fig. 2a) results in its selective removal of both RBP and TTR from plasma, indicating that both proteins are transported in plasma as a complex. The subsequent analysis of the precipitate by Western blotting results in a similar picture as obtained from native plasma (fig. 2a, lane b) and shows that the supernatant is virtually free of RBP and only TTR is left (fig. 2a, lane c). The observation that the supernatant still contains appreciable amounts of TTR after immunoprecipitation using an antibody directed towards RBP supports the fact that only one third of TTR in plasma is associated with RBP [73]. When using a TTR antibody, for immunoprecipitation (fig. $2 \mathrm{~b}$ ) again both TTR and RBP are precipitated from plasma. The remaining RBP in the supernatant is indicative of free RBP not associated with the TTR complex [74].

After protein enrichment with immunoprecipitation, MS can be used for detection of the protein complex, en-

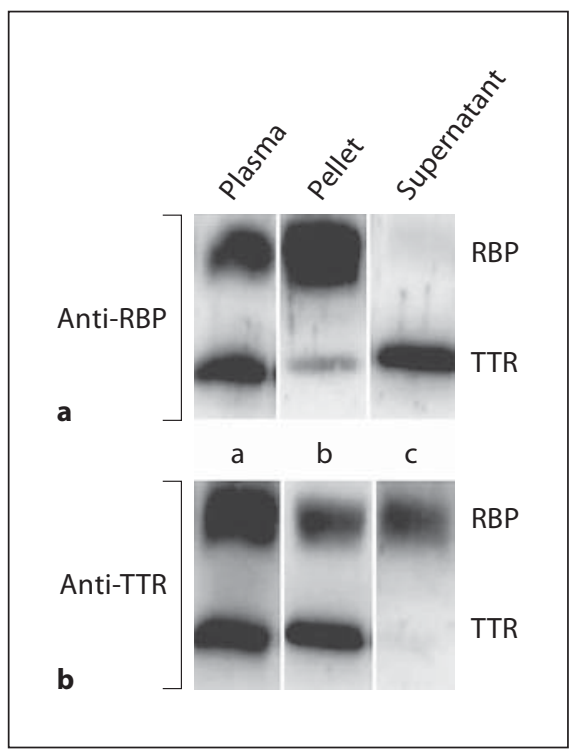

Fig. 2. Interaction of RBP and TTR in blood plasma as shown by immunological enrichment, subsequent one-dimensional-electrophoretic separation and Western blotting. The RBP-TTR-complex was immunopurified from $15 \mu$ l plasma by immunoprecipitation using a polyclonal antibody against human RBP (a) or TTR (b). After extensive washing, the protein complex was subjected to one-dimensional electrophoresis with subsequent Western blotting using polyclonal antibodies against RBP and TTR. Methods used are described in detail elsewhere [30, 84].

abling confirmation that it is indeed TTR. In contrast to Western blotting, much higher mass accuracy is obtained with this method which allows for the identification of various molecular variants of both TTR (fig. 3) and RBP (fig. 4). Using MALDI-TOF-MS for TTR (fig. 3a) not only the native variant of TTR $(13,753 \mathrm{Da})$ but also four variants with higher molecular weight $(\sim 90, \sim 120, \sim 180$ and $\sim 300$ Da larger than native TTR) can be observed [34, 75, 76]. These represent $\mathrm{Cys}^{10}$ adducts for S-sulfonate (TTR$\mathrm{Cys}^{10}-\mathrm{S}_{-} \mathrm{SO}_{3} \mathrm{H}$, mass = 13,841 Da), S-cysteine (TTRCys $^{10}$-S-S-Cys, mass $\left.=13,879 \mathrm{Da}\right)$, S-cysteinylglycine $\left(\right.$ TTR-Cys ${ }^{10}-S-S-C y s G l y$, mass $\left.=13,934\right)$ and S-glutathione $\left(\right.$ TTR-Cys ${ }^{10}-S-S-S G$, mass $\left.=14,083\right)$. The shift in the mass spectrum of TTR variants into its native variant due to treatment with DTT after its immunological enrichment (fig. 3b) confirms that the adducts are formed via the disulfide linkage at $\mathrm{Cys}^{10}$.

RBP in plasma, beside TTR consisting of 183 amino acids with a MW of $\sim 21,060 \mathrm{Da}$, is a second variant that can be regularly observed in healthy individuals (fig. 4a). The mass reduction is due to the post-translational enzymatic removal of one leucin from the C-terminal end. In 


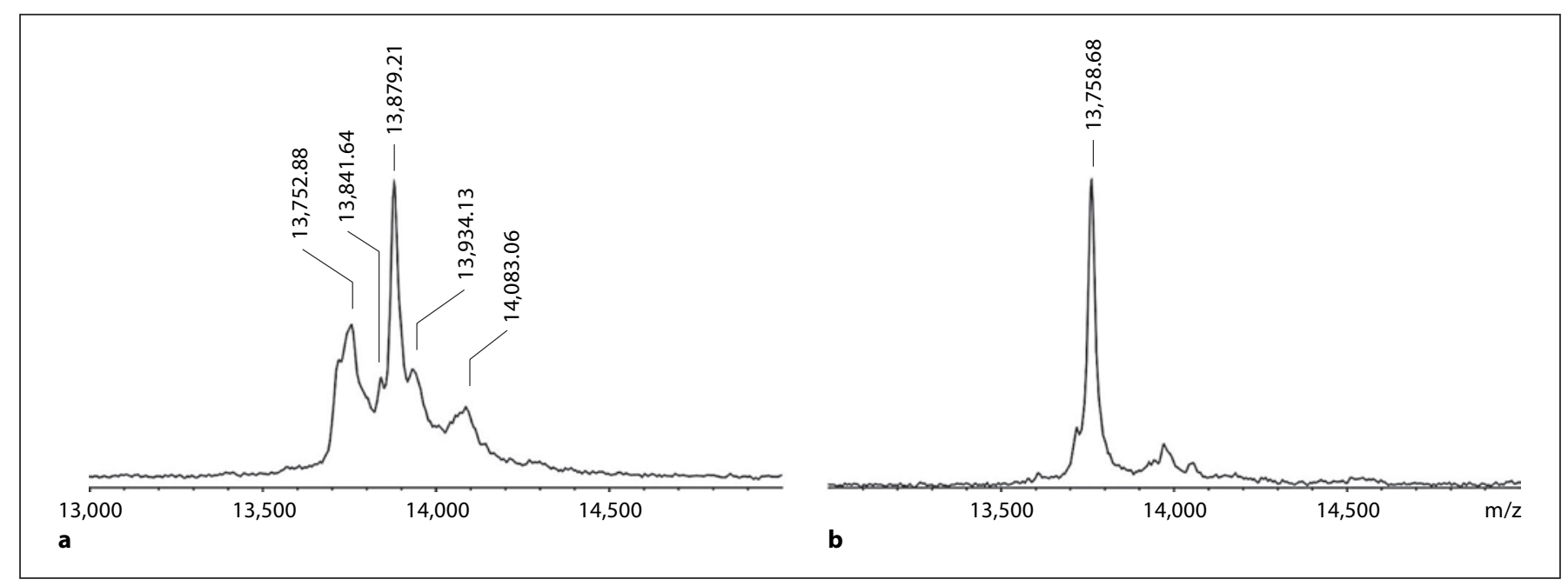

Fig. 3. Mass spectrometry characteristics of the microheterogeneity of human TTR untreated (a) and treated wit DTT (b) isolated from plasma by immunoprecipitation with human anti-TTR using MALDI-TOF-MS. Methods used are described in detail elsewhere [30, 85].

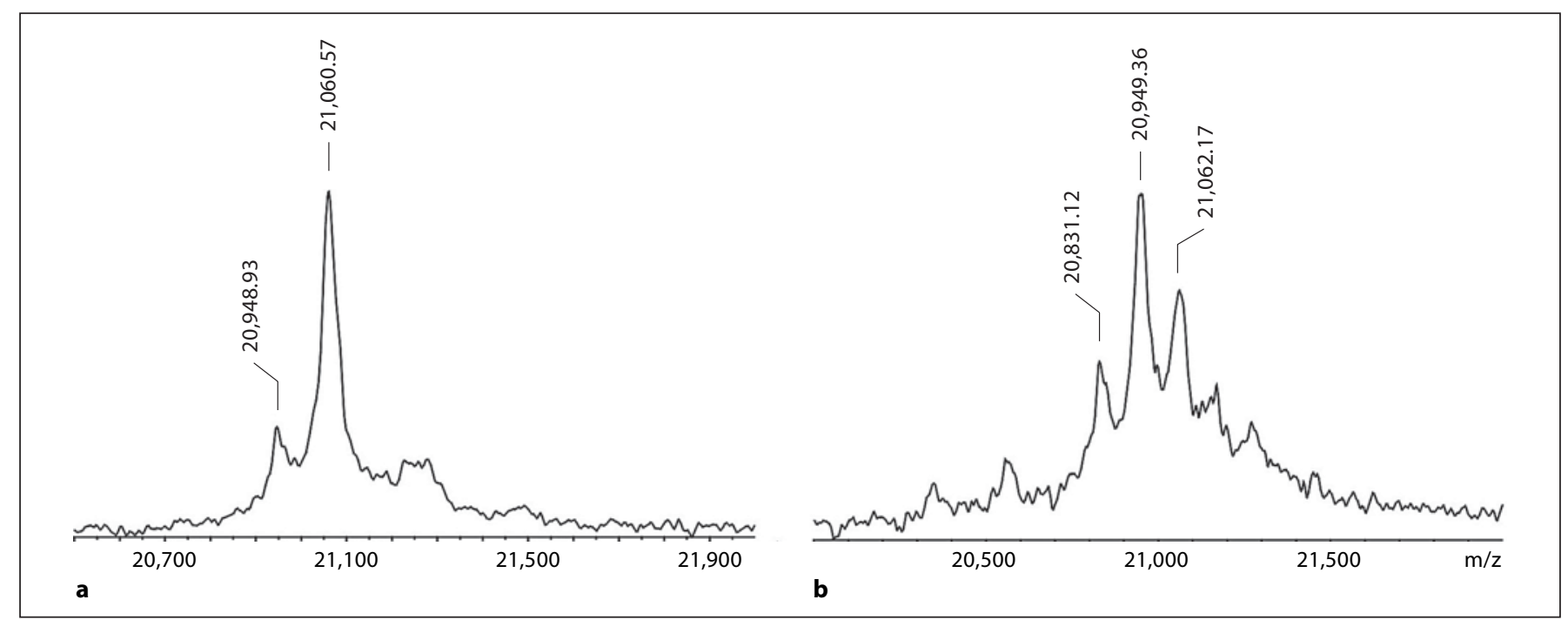

Fig. 4. Mass spectrometry characteristics of the microheterogeneity of human plasma RBP of healthy individuals (a) and of patients with end-stage renal failure (b) isolated from plasma by immunoprecipitation with human anti-RBP using MALDI-TOF-MS. Methods used are described in detail elsewhere [30, 85].

patients with end-stage renal failure a second truncated form with a further removal of a c-terminally positioned leucin can be observed (fig. 4b). The two molecular variants of native RBP, des $\left({ }^{182} \mathrm{Leu}\right) \mathrm{RBP}$ and $\operatorname{des}\left({ }^{182} \mathrm{Leu}-\right.$ $\left.{ }^{183} \mathrm{Leu}\right) \mathrm{RBP}$ are named $\mathrm{RBP}_{1}$ and $\mathrm{RBP}_{2}$, respectively [77].

When examining TTR's behavior under pathophysiological conditions, it is found to be influenced by discrete amino acid substitutions in the case of familial am- yloidosis, whilst the occurrence of normal TTR forms in senile amyloidosis indicates that other metabolic factors are probably involved. Recent studies show that oxidative stress [78] and especially post-translational modifications of TTR at the $\mathrm{Cys}^{10}$ make TTR more amylogenetic [79]. It is not known however if post-translational modifications affect the affinity of the interaction of the RBPTTR complex [71]. 
Additionally, using the RBP-TTR complex, it is possible to show the interference of small molecules with protein-protein interactions. Whereas on the one hand, retinol is the physiological ligand for RBP and initiates the interaction of RBP with TTR, the synthetic retinoid fenretinide as used in the therapy of cancer disturbs the RBP-TTR interaction when associated with RBP due to its bulky hydroxy group [80]. Consequently, a dramatic decrease in RBP plasma levels can be observed [81-83].

\section{Conclusions}

When applying proteomics to nutrition-related research, one has to keep in mind that apart from the analytical complexity, the limitation of these methods still lies particularly in the cost, resolution, reproducibility and throughput. Nevertheless, both the methodologies at hand for proteomics as well as the conceptual strategies are promising for making a significant impact on future nutrition research. This is not only related to studies conducted to confirm the interaction of nutrients with the genome thus responsible for protein expression but more importantly the direct or indirect interaction of nutrients with proteins. Through covalent or non-covalent interactions, functional modifications in the targeted proteins can be observed. These new strategies will give opportunities to establish useful new biomarkers for the validation of efficacy and safety of nutrients with health-promoting effects. Such information will improve our capabilities to perform early diagnosis of diseases and develop prognostic indexes and novel dietary and pharmacological therapies. New biomarkers will have however also the potential for early or even pre-symptomatic recognition of nutrition-related diseases that will allow an efficient intervention to reduce secondary complications.

\section{References}

$\checkmark 1$ Venter JC, Adams MD, Myers EW, et al: The sequence of the human genome. Science 2001;291:1304-1351.

2 Haynes PA, Gygi SP, Figeys D, Aebersold R: Proteome analysis: biological assay or data archive? Electrophoresis 1998; 19: 18621871.

- 3 Hochstrasser DF, Sanchez JC, Appel RD: Proteomics and its trends facing nature's complexity. Proteomics 2002;2:807-812.

4 Molloy MP, Witzmann FA: Proteomics: technologies and applications. Brief Funct Genomic Proteomic 2002;1:23-39.

5 Tyers M, Mann M: From genomics to proteomics. Nature 2003;422:193-197.

-6 Arkin MR, Wells JA: Small-molecule inhibitors of protein-protein interactions: progressing towards the dream. Nat Rev Drug Discov 2004;3:301-317.

7 Barnes S, Kim H: Nutriproteomics: identifying the molecular targets of nutritive and non-nutritive components of the diet. J Biochem Mol Biol 2004;37:59-74.

8 Petricoin EF, Liotta LA: Clinical applications of proteomics. J Nutr 2003;133:2476S2484S.

-9 Corthesy-Theulaz I, den Dunnen JT, Ferre P, Geurts JM, Muller M, van Belzen N, van Ommen B: Nutrigenomics: the impact of biomics technology on nutrition research. Ann Nutr Metab 2005;49:355-365.

10 Daniel H, tom Dieck H: Nutrient-gene interactions: a single nutrient and hundreds of target genes. Biol Chem 2004;385:571-583.
11 Davis CD, Milner J: Frontiers in nutrigenomics, proteomics, metabolomics and cancer prevention. Mutat Res 2004;551:51-64.

12 Fuchs D, Winkelmann I, Johnson IT, Mariman E, Wenzel U, Daniel H: Proteomics in nutrition research: principles, technologies and applications. Br J Nutr 2005;94:302314.

13 Kaput J, Rodriguez RL: Nutritional genomics: the next frontier in the postgenomic era. Physiol Genomics 2004;16:166-177.

14 Muller M, Kersten S: Nutrigenomics: goals and strategies. Nat Rev Genet 2003;4:315322.

15 Mutch DM, Wahli W, Williamson G: Nutrigenomics and nutrigenetics: the emerging faces of nutrition. FASEB J 2005;19:16021616.

16 Trayhurn P: Nutritional genomics - 'nutrigenomics'. Br J Nutr 2003;89:1-2.

17 Anderson NL, Anderson NG: Proteome and proteomics: new technologies, new concepts, and new words. Electrophoresis 1998;19: 1853-1861.

18 Anderson NL, Anderson NG: The human plasma proteome: history, character, and diagnostic prospects. Mol Cell Proteomics 2002;1:845-867.

19 Forterre S, Raila J, Schweigert FJ: Protein profiling of urine from dogs with renal disease using ProteinChip analysis. J Vet Diagn Invest 2004;16:271-277.

20 Gericke B, Koebnick C, Reimann M, Forterre S, Zunft HJF, Schweigert FJ: Influence of hormone replacement therapy on proteomic pattern in serum of postmenopausal women. Maturitas 2005;51:334-342.
21 Petricoin EF, Ornstein DK, Paweletz CP, Ardekani A, Hackett PS, Hitt BA, Velassco A, Trucco C, Wiegand L, Wood K, Simone CB, Levine PJ, Linehan WM, Emmert-Buck MR, Steinberg SM, Kohn EC, Liotta LA: Serum proteomic patterns for detection of prostate cancer. J Natl Cancer Inst 2002;94:15761578.

22 Fuchs D, de Pascual-Teresa S, Rimbach G, Virgili F, Ambra R, Turner R, Daniel H, Wenzel U: Proteome analysis for identification of target proteins of genistein in primary human endothelial cells stressed with oxidized LDL or homocysteine. Eur J Nutr 2005;44:95-104.

-23 Gianazza E, Veber D, Eberini I, Buccellato FR, Mutti E, Sironi L, Scalabrino G: Cobala$\min \left(\right.$ vitamin $B_{12}$ ) deficiency-induced changes in the proteome of rat cerebrospinal fluid. Biochem J 2003;374:239-246.

24 Linke T, Ross AC, Harrison EH: Profiling of rat plasma by surface-enhanced laser desorption/ionization time-of-flight mass spectrometry, a novel tool for biomarker discovery in nutrition research. J Chromatogr A 2004;1043:65-71.

- 25 Tosco A, Siciliano RA, Cacace G, Mazzeo MF, Capone R, Malorni A, Leone A, Marzullo L: Dietary effects of copper and iron deficiency on rat intestine: a differential display proteome analysis. J Proteome Res. 2005;4:1781-1788.

26 Park JY, Seong JK, Paik YK: Proteomic analysis of diet-induced hypercholesterolemic mice. Proteomics 2004;4:514-523. 
-27 Cesareni G, Ceol A, Gavrila C, Palazzi LM, Persico M, Schneider MV: Comparative interactomics. FEBS Lett 2005;579:18281833.

-28 McCormick F: Small-molecule inhibitors of cell signaling. Curr Opin Biotechnol 2000; 11:593-597.

$\checkmark 29$ Park D, Lee S, Bolser D, Schroeder M, Lappe $\mathrm{M}, \mathrm{Oh} \mathrm{D}, \mathrm{Bhak}$ J: Comparative interactomics analysis of protein family interaction networks using PSIMAP (protein structural interactome map). Bioinformatics 2005;21: 3234-3240.

-30 Schweigert FJ: Characterisation of protein microheterogeneity and protein complexes using on-chip immunoaffinity purificationmass spectrometry. Brief Funct Genomic Proteomic 2005;4:7-15.

>31 Gburek J, Verroust PJ, Willnow TE, Fyfe JC, Nowacki W, Jacobsen C, Moestrup SK, Christensen EI: Megalin and cubilin are endocytic receptors involved in renal clearance of hemoglobin. J Am Soc Nephrol 2002;13: 423-430.

\32 Lopez F, Pichereaux C, Burlet-Schiltz O, Pradayrol L, Monsarrat B, Esteve JP: Improved sensitivity of biomolecular interaction analysis mass spectrometry for the identification of interacting molecules. Proteomics 2003;3: 402-412.

$\checkmark 33$ Natsume T, Nakayama H, Isobe T: BIA-MSMS: biomolecular interaction analysis for functional proteomics. Trends Biotechnol 2001;19:S28-S33.

34 Schweigert FJ, Wirth K, Raila J: Characterization of the microheterogeneity of transthyretin in plasma and urine using SELDITOF-MS immunoassay. Proteome Sci 2004; 2:5.

-35 Tolson J, Bogumil R, Brunst E, Beck H, Elsner R, Humeny A, Kratzin H, Deeg M, Kuczyk M, Mueller GA, Mueller CA, Flad T: Serum protein profiling by SELDI mass spectrometry: detection of multiple variants of serum amyloid $\alpha$ in renal cancer patients. Lab Invest 2004;84:845-856.

-36 Apweiler R, Hermjakob H, Sharon N: On the frequency of protein glycosylation, as deduced from analysis of the SWISS-PROT database. Biochim Biophys Acta 1999;1473: 4-8.

-37 Banks RE, Dunn MJ, Hochstrasser DF, Sanchez JC, Blackstock W, Pappin DJ, Selby PJ: Proteomics: new perspectives, new biomedical opportunities. Lancet 2000;356:17491756.

$\checkmark 38$ Baumann M, Meri S: Techniques for studying protein heterogeneity and post-translational modifications. Expert Rev Proteomics 2004;1:207-217.

-39 Davis BG: Biochemistry. Mimicking posttranslational modifications of proteins. Science 2004;303:480-482.

40 Hancock WS: Glycosylation, who cares? J Proteome Res 2002;1:297.
41 Mann M, Jensen ON: Proteomic analysis of post-translational modifications. Nat Biotechnol 2003;21:255-261.

42 Kroll J, Rawel H, Rohn S: A review. Reactions of plant phenolics with food proteins and enzymes under special consideration of covalent bonds. Food Sci Technol Res 2003;9: 205-218.

43 Rawel HM, Meidtner K, Kroll J: Binding of selected phenolic compounds to proteins. Agric Food Chem 2005;53:4228-4235.

44 Rawel HM, Rohn S, Kroll J, Schweigert FJ: Surface enhanced laser desorption ionization-time of flight-mass spectrometry analysis in complex food and biological systems. Mol Nutr Food Res 2005;49:1104-1111.

45 Rawel HM, Rohn S, Kroll J: Influence of a sugar moiety (rhamnosylglucoside) at 3-O position on the reactivity of quercetin with whey proteins. Int J Biol Macromol 2003;32: 109-120.

46 Seifert A, Rawel H, Harding SE, Kroll J: Characterization of bovine serum albumin/ chlorogenic acid solution mixtures by analytical ultracentrifugation. Prog Colloid Polymer Sci 2004;127:83-88.

47 Rawel H, Kroll J, Haebel S, Peter MG: Reactions of a glucosinolate breakdown product (benzyl isothiocyanate) with myoglobin. Phytochemistry 1998;48:1305-1311.

48 Rohn S, Rawel H, Wollenberger U, Kroll J: Enzymatical behaviour of $\alpha$-chymotrypsin after derivatization with phenolic compounds. Nahrung 2003;47:325-329.

49 Knowles LM, Milner JA: Diallyl disulfide induces ERK phosphorylation and alters gene expression profiles in human colon tumor cells. J Nutr 2003;133:2901-2906.

50 Dinkova-Kostova AT: Protection against cancer by plant phenylpropenoids: induction of mammalian anticarcinogenic enzymes. Mini Rev Med Chem 2002;2:595610.

51 Beauchamp GK, Keast RS, Morel D, Lin J, Pika J, Han Q, Lee CH, Smith AB, Breslin PA: Phytochemistry: ibuprofen-like activity in extra-virgin olive oil. Nature 2005;437:4546.

52 Archakov AI, Govorun VM, Dubanov AV, Ivanov YD, Veselovsky AV, Lewi P, Janssen P: Protein-protein interactions as a target for drugs in proteomics. Proteomics 2003;3: 380-391

53 Jenkins JL, Shapiro R: Identification of small-molecule inhibitors of human angiogenin and characterization of their binding interactions guided by computational docking. Biochemistry 2003;42:6674-6687.

54 Loregian A, Marsden HS, Palu G: Proteinprotein interactions as targets for antiviral chemotherapy. Rev Med Virol 2002;12:239262.

55 Purkey HE, Dorrell MI, Kelly JW: Evaluating the binding selectivity of transthyretin amyloid fibril inhibitors in blood plasma. Proc Natl Acad Sci USA 2001;98:5566-5571.
56 Veselovsky AV, Ivanov YD, Ivanov AS, Archakov AI, Lewi P, Janssen P: Protein-protein interactions: mechanisms and modification by drugs. J Mol Recognit 2002;15: 405-422.

57 Gadek TR, Nicholas JB: Small-molecule antagonists of proteins. Biochem Pharmacol 2003;65:1-8.

58 Pagliaro L, Felding J, Audouze K, Nielsen SJ, Terry RB, Krog-Jensen C, Butcher S: Emerging classes of protein-protein interaction inhibitors and new tools for their development. Curr Opin Chem Biol 2004;8:442-449.

59 Grant SG, Husi H: Proteomics of multiprotein complexes: answering fundamental questions in neuroscience. Trends Biotechnol 2001;19:S49-54.

60 Figeys D, McBroom LD, Moran MF: Mass spectrometry for the study of protein-protein interactions. Methods 2001;24:230239.

61 Nair KS, Jaleel A, Asmann YW, Short KR, Raghavakaimal S: Proteomic research: potential opportunities for clinical and physiological investigators. Am J Physiol 2004; 286:E863-E874.

62 Arthur JM: Proteomics. Curr Opin Nephrol Hypertens 2003;12:423-430.

63 Hanash S: Disease proteomics. Nature 2003; 422:226-232.

64 Ingenbleek Y, Young V: Transthyretin (prealbumin) in health and disease: nutritional implications. Annu Rev Nutr 1994;14:495533.

65 Palha JA: Transthyretin as a thyroid hormone carrier: function revisited. Clin Chem Lab Med 2002;40:1292-1300.

66 Chang MH, Hua CT, Isaac EL, Litjens T, Hodge G, Karageorgos LE, Meikle PJ: Transthyretin interacts with the lysosome-associated membrane protein (LAMP-1) in circulation. Biochem J 2004;382:481-489.

67 Lasztity N, Biro L, Nemeth E, Pap A, Antal $\mathrm{M}$ : Protein status in pancreatitis-transthyretin is a sensitive biomarker of malnutrition in acute and chronic pancreatitis. Clin Chem Lab Med 2002;40:1320-1324.

68 Zhang Z, Bast RC Jr, Yu Y, Li J, Sokoll LJ, Rai AJ, Rosenzweig JM, Cameron B, Wang YY, Meng XY, Berchuck A, Van Haaften-Day C, Hacker NF, de Bruijn HW, van der Zee AG, Jacobs IJ, Fung ET, Chan DW: Three biomarkers identified from serum proteomic analysis for the detection of early stage ovarian cancer. Cancer Res 2004;64:5882-5890.

69 Schweigert FJ, Sehouli J: Transthyretin, a biomarker for nutritional status and ovarian cancer. Cancer Res 2005;65:1114.

70 Blomhoff R: Transport and metabolism of vitamin A. Nutr Rev 1994;52:S13-S23.

$>71$ Monaco HL: The transthyretin-retinolbinding protein complex. Biochim Biophys Acta 2000;1482:65-72.

72 Zanotti G, Berni R: Plasma retinol-binding protein: structure and interactions with retinol, retinoids, and transthyretin. Vitam Horm 2004;69:271-295. 
73 Rosales FJ, Chau KK, Haskell MH, Shankar AH: Determination of a cut-off value for the molar ratio of retinol-binding protein to transthyretin (RBP:TTR) in Bangladeshi patients with low hepatic vitamin A stores. J Nutr 2002;132:3687-3692.

-74 Blomhoff R, Green MH, Berg T, Norum KR: Transport and storage of vitamin A. Science 1990;250:399-404.

-75 Kiernan UA, Tubbs KA, Gruber K, Nedelkov D, Niederkofler EE, Williams P, Nelson RW: High-throughput protein characterization using mass spectrometric immunoassay. Anal Biochem 2002;301:49-56.

-76 Zhang Q, Kelly JW: Cys10 mixed disulfides make transthyretin more amyloidogenic under mildly acidic conditions. Biochemistry 2003;42:8756-8761.

-77 Jaconi S, Rose K, Hughes GJ, Saurat JH, Siegenthaler G: Characterization of two post-translationally processed forms of human serum retinol-binding protein: altered ratios in chronic renal failure. J Lipid Res 1995;36:1247-1253.
78 Tajiri T, Ando Y, Hata K, Kamide K, Hashimoto M, Nakamura M, Terazaki H, Yamashita T, Kai H, Haraoka K, Imasato A, Takechi K, Nakagawa K, Okabe H, Ishizaki T: Amyloid formation in rat transthyretin: effect of oxidative stress. Clin Chim Acta 2002;323: 129-137.

79 Takaoka Y, Ohta M, Miyakawa K, Nakamura O, Suzuki M, Takahashi K, Yamamura K, Sakaki Y: Cysteine 10 is a key residue in amyloidogenesis of human transthyretin Val30Met. Am J Pathol 2004;164:337-345.

80 Malone W, Perloff M, Crowell J, Sigman C, Higley H: Fenretinide: a prototype cancer prevention drug. Expert Opin Investig Drugs 2003;12:1829-1842.

81 Berni R, Clerici M, Malpeli G, Cleris L, Formelli F: Retinoids: in vitro interaction with retinol-binding protein and influence on plasma retinol. FASEB J 1993;7:1179-1184.
82 Formelli F, Carsana R, Costa A, Buranelli F, Campa T, Dossena G, Magni A, Pizzichetta $\mathrm{M}$ : Plasma retinol level reduction by the synthetic retinoid fenretinide: a one year followup study of breast cancer patients. Cancer Res 1989;49:6149-6152.

83 Holven KB, Natarajan V, Gundersen TE, Moskaug JO, Norum KR, Blomhoff R: Secretion of $\mathrm{N}$-(4-hydroxyphenyl)retinamideretinol-binding protein from liver parenchymal cells: evidence for reduced affinity of the complex for transthyretin. Int J Cancer 1997; 71:654-659.

84 Schweigert FJ, Steinhagen B, Raila J, Siemann A, Peet D, Buscher U: Concentrations of carotenoids, $\alpha$-tocopherol and retinol in serum and follicular fluid of women undergoing IVF. Hum Reprod 2003;18:12591264.

85 Gericke B, Raila J, Sehouli J, Haebel S, Konsgen D, Mustea A, Schweigert FJ: Microheterogeneity of transthyretin in serum and ascitic fluid of ovarian cancer patients. BMC Cancer 2005;5:133 